\title{
APORTES AL CONOCIMIENTO DE LA HIDATIDOSIS COMO ZOONOSIS URBANA (1)
}

\author{
Edmundo LARRIEU (2), Jorge IRIARTE (3) \& Omar ZAVALETA (4)
}

\section{R E S U M E N}

En la República Argentira, la hidatidosis constituye un serio problema que afecta a la salud publica y tiene graves repercusiones socioeconomicas.

Las fuertes corrientes urbanîsticas han traido consigo el traslado de algunas costumbres rurales hacia los centros poblados. A partir de ello la hidatidosis en las areas endemicas ha adquirido importancia como zoonosis urbana.

Si bien las cifras de infección canina halladas (1.12\%) son significativamente inferiores que en las áreas rurales de la misma región, la capacidad potencial de infectar al hombre es muy superior en canes domiciliados en áreas de gran densidad demográica. Las altas tasas de infección numana halladas son demostrativas de los aspectos señalados.

UNITERMOS: Hidatidosis; Zoonosis.

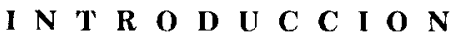

En la Republica Argentina, la hidatidosis constituye un serio problema que afecta a la Salud Publica y tiene graves repercusiones so cioeconomicas (3).

El hombre y el ganado contraen la hidatidosis al ingerir los huevos de la tenia Equino. coccus granulosus eliminados en la materia fe cal del perro. Una vez llegados al intestino, el embrión atraviesa la pared intestinal y se pue den alojar en el higado, pulmones o con menor frecuencia en otros órganos en los que se desar rolla la forma larval o quística del parásito ${ }^{3}$.

E1 perro contrae la enfermedad cuando in giere vísceras con quistes hidatidicos fértiles. Es tos contienen protoescólices que se transforman en el intestino del perro en tenias adultas, las que comienzan a producir huevos infestantes después de transcurridos 47 a 61 dias ${ }^{3}$.

Este ciclo, en el cual los dos eslabones principales son el perro y el ovino, determina que las áreas de mayor ocurrencia de la enfermedad, y en donde el riesgo de enfermar para el hombre sea mayor, lo constituyan las zonas ganaderas, siendo por lo tanto una zoonosis típicamente rural.

Sin embargo, las fuertes corrientes urbanísticas y el éxodo de parte de las poblaciones campesinas hacia los centros poblados, ha traído

\footnotetext{
(1) Trabajo cooperativo entre las Subsecretarias de Salud de las Provincias de Rio Negro, Chubut y Neuquén (Argentina).

(2) Jefe Departamento Zoonosis (Pvcia. Rio Negro).

Prof. Catedra de Epidemiologia, Facultad C. Veterinarias (La Pampa)

(3) Jefe Departamento Zoonosis (Pvcia. Chubut)

(3) Jefe Departamento Zoonosis (Pvcia. Neuquén).

Correspondència para: Dr. Edmundo Larrieu. Ministerio de Salud Publica. (8500) Viedma, Rio Negro, Argentina
} 
LARRIEU, E.; IRIARTE, J. \& ZAVALETA, O. - Aportes al conocimiento de la hidatidosis como zoonosis urbana. Rev.

Inst. Med. trop. São Paulo, 30 (1): 28-31, 1988.

consigo el traslado de algunas costumbres rura les como la explotación doméstica de animales para consumo, a pesar de la reducción del espa cio y de la vivienda, aumentando en consecuen cia el contacto y los riesgos de enfermar.

De esta forma, algunas zoonosis, consideradas históricamente como rurales comienzan a presentar una elevada ocurrencia urbana.

El presente informe pretende documentar la ocurrencia urbana de la hidatidosis, a los fines de adecuar las estrategias de control a esta nue va situación, y estimar las causales de la trans misión urbana, de carácter autóctono, con el ob jeto de estimular investigaciones especiales so bre el tema.

\section{MATERIALES Y METODOS}

En el sur de la Argentina, las Provincias de Neuquén, Río Negro, Chubut y Tierra del Fuego mantienen Programas de Control de la Hidati dosis que plantean el corte del ciclo de trans misión del Equinococcus granulosus ${ }^{3.6}$.

Dichos Programas parten de una etapa pre via de diagnóstico de la situación que compren de la determinación de las tasas de infección hidatídica en el perro, el ovino y el hombre y, subsiguientenente efectúan acciones de control con Praziquantel en la periodicidad establecida; eliminación de las fuentes de infección de perros mediante la promoción de la construcción de carneaderos de estancia y mataderos urbanos aptos; y educación sanitaria buscando modificar hábitos de conducta condicionantes de la enfer medad $^{1.3}$. Paralelamente, se mantienen acciones de vigilancia, basadas en el análisis coporopara sitológico efectuado a partir del vermífugo brom hidrato de arecolina (perros), registro de deco misos en mataderos (ovinos), registro y notifica ción de casos operados y realización de encues tas serológicas basadas en la Doble Difusión pa ra Arco 5 y ecográficas en la búsqueda de imáge nes compatibles en poblaciones aparentemente sanas (hombre). Los grupos humanos catastra dos, en su mayor parte comprenden escolares (7 a 13 años) y conscriptos (18 a 21 años $)^{1,3}$.

La información obtenida es recogida en un sistema íntegrado de vigilancia epidemiológica regional.
Las diferentes técnicas empleadas, sus crite rios de positividad y la metodología de la selec ción de muestras, han sido convenientemente descriptas ${ }^{1} \cdot 2.3 .4 .8$. Para el presente trabajo se considera exclusivamente la información obte nida por el sistema de vigilancia de las áreas urbanas de la Patagonia.

Dado el carácter eminentemente rural de las actividades desplegadas por los Programas de Control, la información existente no es completa en todos los ítems estudiados, pero sí es abarcativo y representativo de todo el mapa regional.

\section{RESULTADOS}

El cúmulo de actividades sistematizadas en ejecución ha permitido en el tiempo, recoger in formación, no solamente de las áreas rurales en las cuales se hallan centradas las acciones de control, sino de las grandes unidades urbanas, poniéndose de manifiesto situaciones epidemio lógicas no descriptas hasta el momento.

Así, en el Cuadro 1, se presenta la tasa de prevalencia Equinococcosica canina, estableci da en el $1.12 \%$.

CUADRO 1

Equinococcosis canina urbana Patagonia Argentina -... 1984:85

\begin{tabular}{lrr}
\hline Localidad & Perros estudiados & Positivos (\%) \\
\hline Puerto Madryn & 903 & $16(1.77)$ \\
Rawson & 479 & 10, \\
Trelew & 1080 & $25(2.31)$ \\
C. Rivadavia & 3469 & $10(0.28)$ \\
Esquel & 279 & $22(7.90)$ \\
Cinco Saltos & 140 & $(0)$, \\
Cipolletti & 177 & $3(1.69)$ \\
Viedma & 482 & $4(0.83)$ \\
Alumine & 219 & $4(1.82)$ \\
Junín de los Andes & 430 & $6(1.39)$ \\
Piedra del Aguila & 191 & $1052)$ \\
\hline \multicolumn{1}{c}{ TOTAL } & 7849 & $88(1.12)$ \\
\hline
\end{tabular}

La situación urbana de la hidatidosis huma na se presenta en los Cuadros 2 y 3 y representa el porcentaje de población asintomática porta dora de quistes hidatídicos existentes en los principales centros poblados, determinado en 
LARRIEU, E ; IRIARTE, J. \& ZAVALETA, O. - Aportes al conocimiento de la hidatidosis como zoonosis urbana Rev. Inst. Med. trop. São Paulo, 30 (1): 28 31, 1988

base a encuestas ecográficas $16.46 \%$ de imagenes compatibles), y encuestas serológicas $(0.27 \%$ de positividad).

CUADRO 2

Gatastro ecografieo

En poblacion humana asintomatica de areas urbanas Patagonia, Argentina ... 1986

\begin{tabular}{lcr} 
Localidad & $\begin{array}{c}\text { Ecografias } \\
\text { realizadas }\end{array}$ & $\begin{array}{c}\text { Imagenes } \\
\text { compatibles N }(\%)\end{array}$ \\
\hline Cinco Saltos & 85 & $617.05)$ \\
Viedma & 194 & $73.60)$ \\
Loncopuc & 278 & $23(8.27)$ \\
\hline \multicolumn{1}{c}{ TOTAL } & 557 & $36(6.46)$ \\
\hline
\end{tabular}

CUADFO 3

Catastro serologico

En poblacion humana asintomatica

de areas urbanas, Patagonia. Argentina $\quad . . .198586$

\begin{tabular}{lcc}
\hline Localidad & Encuestas realizadas & Positivas $\mathrm{N}(\%)$ \\
\hline Viedma & 1101 & 410.36 । \\
Cipolletti Roca & 3417 & $210.05)$ \\
Trelew & 1329 & $510.37)$ \\
Neuquen & 1427 & $910.63)$ \\
\hline \multicolumn{1}{c}{ TOTAL } & 7274 & $20(0.27)$ \\
\hline
\end{tabular}

\section{DISCUSION}

El hallazgo de canes infectados por Equinococcus granulosus en áreas urbanas puede ser explicado a partir de mecanismos de infección dados por el traslado de la práctica de alimen. tación de perros con achuras crudas del campo a la ciudad, lo cual ocurre a partir de la obtención de vísceras de mataderos con deficiencias higié nico sanitarias, o de su compra a faenadores clandestinos, sumado a que los mismos perros ya pueden traer la equinococcósis antes de lle gar a la ciudad o infectarse recurrentemente en el caso de propietarios agripecuarios con domi cilio rutinario en la ciudad.

Si bien las cifras de infección canina halladas son significativamente menores que las de áreas rurales, para la misma región $\mathrm{n}^{\beta .7}$, indudablemente la capacidad potencial de infectar al hombre será mayor en canes domiciliados en áreas de gran densidad demografica en relacion a canes aislados en la extensa estepa patagónira

Este aspecto, se refleja en los hallazgos de portadores humanos en las areas urbanas, que. a la consulta, reconocen dos origenes: poblacion migrante del campo a la ciudad con anteceren tes de domicilio en áreas endémicas y población sin antecedentes de domicilio en areas rurales endèmicas.

Si bién, las infecciones en el primer grupo pueden ser explicadas a partir de sus antece dentes, en el segundo caso puede sospecharse una tasa de trasmisión elevada perro hombre en el medio urbano.

Estos aspectos no han sido hasta el momen to cuantificados y requiéren de investigaciones específicas para la determinación de la gravedad de la trasmisión urbana.

En cualquier caso, los hallazgos de las en cuestas plantean un desafio a la Salud Pública, en el sentido de lograr una capacidad de detec. ción temprana para esa gran masa de portadores existente, y una respuesta en la capacidad instalada para la atención quirúrgica de esa de manda generada, que actualmente no siempre se está en condiciones de satisfacer.

Debe considerar se, al respecto, que los mayores y a veces únicos esfuerzos diagnósticos se han volcado hacia los grupos humanos de mayor exposición al riesgo, afincados en el me dio rural.

Si extrapolamos la tasa de positividad halla da en las encuestas serológicas $(0.27 \%)$ a una población urbana que ronda el millón de habitantes, podríamos estimar en 2700 el número de personas infectadas. Si consideramos los resul tados de las encuestas ecográficas, aún tratán dose solamente de imágenes compatibles, la es timación del iúmero de portadores sin sintomas clínicos alcanza los 64.600 casos. Estas cifras son concordantes con el número de operados anual. mente en la Patagonia (más de 500 casos/año con domicilio en la región).

Paralelamente se plantea el desafio a los Programas de Control estructurados históricamente para el combate contra la hidatidosis en 
áreas rurales a los fines de adecuar sus estrategias para enfrentar con éxito esta nueva situa. ción.

\section{SUMMARY}

Contribution to Hydatidosis as an urban zoonosis

In Argentina hydatidosis is a serious problem of Public Health with socioeconomic effects.

Strong urbanistic populational streams brought from the country local habits to urban areas. Hydatidosis became them an urban zoonosis.

In spite of data on canine infection found (1.12\%) are lower than those found in rural areas from the same region, the potential capacity to infect humans is higher in dogs from areas of high demographic density. The high incidences of human infections found are in accordance with this idea.

\section{BIBLIOGRAFIA}

1. ABDUSSALAM, M.; ECKERT, J \& GEMMEL, M - Pau tas para la Vigilancia, Prevención y Control de la Equino coccosis. Zurich, FAO/UNEP/OMS, 1982

2. COLTORTI, E. \& VARELA DIAZ, V. - Inmunología e inmunodiagnóstico de la hidatidosis humana. Med. Argent., $6: 135 \cdot 147,1978$.

3. DE ZAVALETA, O : LARRIEU, E : IRIARTE, J ; GUAR NERA, E.: NADER, E. \& BARBUTO, S. -- Norma técnica y manual de procedimientos para el control de la hidati dosis en la República Argentina. Buenos Aires, Ministerio de Salud y Acción Social, 1986

4. FRIDER, B.: LARRIEU, E.; VARGAS, F. \& ODRIOZO LA, M. - Catastro ecográfico, serológico y radiológico en hidatidosis humana. Aportes a un programa de control. Acta Gastro-ent. Lat-amer., 4: 199-211, 1985.

5. LARRIEU, E,; ALVAREZ, T. \& CAVAGIÓN, J. - Aportes a la vigilancia epidemiológica de ha hidatidosis. Bol. chil, Parasit. (En prensa) 1986.

6. LARRIEU, E; ARCE BORDA, L. \& REALES, H -_Lucha contra la hidatidosis en la República Argentina, situación actual. Gac. vet. (B. Aires) 378: $217235,1983$.

7. LARRIEU, E.; DE ZAVALETA, O; IRIARTE, J. \& BITSCH, A. - Sistema de vigilancia epidemiológica de la hidatidosis en la Región Patagónica Argentina. Vet. Argent. 19: 843-853, 1985

8. SCHANTZ, P. - Guia para el empleo del Bromhidrato de Arecolina en el Diagnóstico de la Infección por Echinococcus granulosus en el perro. Bol. chil. Parasit., 28: 8190. 1973

Recebido para publicaçāo em 11:5/87 